Murex trunculus, has strong nicotine-like effects but almost no muscarinic effects ${ }^{5}$. For that reason the physiological effects from extracts of the Neptunea glands probably are not due to the presence of murexine. In Hokkaido in Japan food poisoning has been caused by eating Neptunea arthritica, and it was found that only the salivary glands and no other parts of the molluses were poisonous ${ }^{6}$.

Neptunea, like Buccinum, is a carnivorous animal, but its feeding habits are not known. Presumably, the secretion from the salivary glands is used to paralyse other animals which serve it as prey.

Marine Zoological Station, RAGNAR FäNGE Kristineberg, and

Department of Zoophysiology, University of Lund, Sweden. April 8.

${ }^{1}$ Welsh, J. H., Nature, 173, 955 (1954).

${ }^{2}$ Fange, R., and Mattisson, A., Ark. Zool. (in the press).

${ }^{3}$ Augustinsson, K.-B., and Grahn, M., Acta Chem. Scand., 7, 906 (1953).

4 Welsh, J. H., J. Mar. Biol. Assoc. U,K., 35, 193 (1956).

- Erspamer, V., and Benati, O., Biochem. Z., 324, 66 (1953).

- Asano, M., Bull. Jap. Soc. Sci. Fish., 17, 283 (1952).

\section{Action of Copper on Mammalian $\beta$-Glucuronidase}

IN studying the inhibition of partially purified mammalian $\beta$-glucuronidase by heavy metal ions, we have found that the cupric ion is a moderate inhibitor, and is potentiated by cysteine. This action of cysteine appears to be limited by the formation of eystine, since the latter reverses inhibition by copper and by other metals. Sodium bisulphite and ascorbic acid were therefore examined as alternative reducing agents. Neither of these agents by itself had any effect on the enzyme activity, but they had

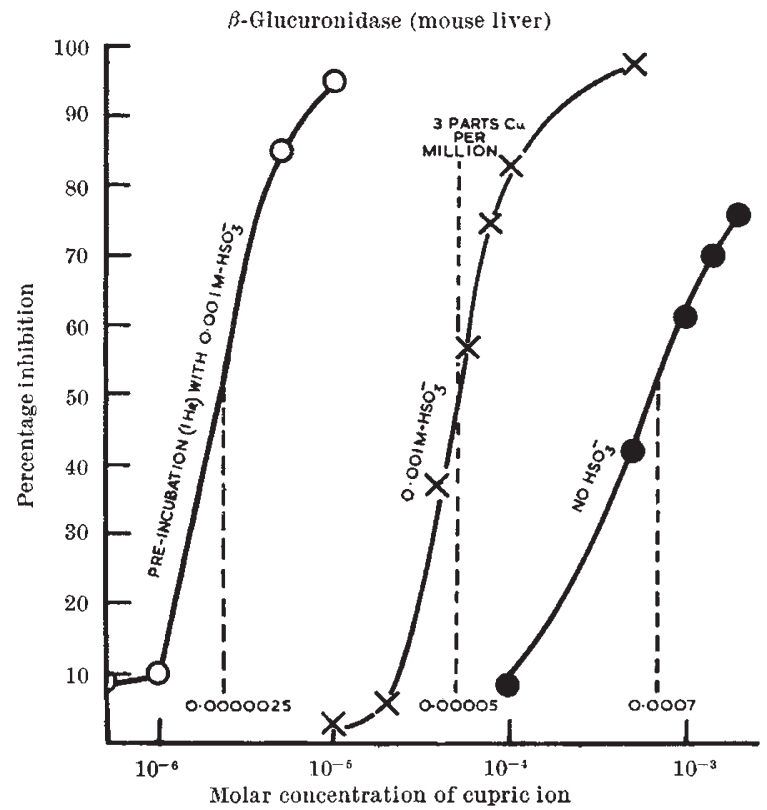

Fig. 1. The effect of cupric ions in presence and absence of bisulphite on the enzymic hydrolysis of $0.00063 M$-phenolphthalein glucuronide in $1 \mathrm{hr}$. at $37^{\circ} \mathrm{C}$. and $p \mathrm{H} 5 \cdot 2$, as compared with the effect of pretreating the enzyme at $37^{\circ} \mathrm{C}$. with these reagents at the $p \mathrm{H}$ of assay an identical action in potentiating inhibition by the cupric ion, as shown in Fig. 1; this process was instantaneous, there being no increase in inhibition on prolonged incubation with the substrate. In the presence of ascorbic acid or bisulphite, the inhibitory power of $\mathrm{Cu}^{++}$was of the same order as that of $\mathrm{Ag}^{+}$ or $\mathrm{Hg}^{++}$, neither of which was potentiated by the reducing agents. A feasible explanation of these results is that copper inhibition is due to the cuprous, and not the cupric, ion.

These experiments may explain conflicting statements in the literature on inhibition of $\beta$-glucuronidase by ascorbic acid, and may have some bearing on the inhibition of sulphatase by bisulphite ${ }^{2}$.

When the enzyme $\beta$-glucuronidase was incubated in the presence of cupric ions and bisulphite at $37^{\circ} \mathrm{C}$. for $1 \mathrm{hr}$. prior to addition of substrate for assay, the inhibition was enormously increased (Fig. 1). it was necessary to incubate all three components, enzyme, cupric ion and bisulphite, simultaneously, and the process was arrested by addition of substrate. The inhibitory power of $\mathrm{Ag}^{+}$and $\mathrm{Hg}^{++}$was also increased in this type of experiment, but ascorbic acid could not replace bisulphite in this reaction. It is concluded that we are measuring here an alteration in the actual enzyme molecule.

G. A. LeVvy

Rowett Research Institute, Bucksburn,

Aberdeenshire. April 5.

1 Marsh, C. A., Biochem. J., 59375 (1955).

${ }^{2}$ Roy, A. B., Biochem. J., 59, 8 (1955).

\section{Structure of Brain Ganglioside}

THE brain gangliosides of Klenk $^{\mathbf{1}}$ are macromolecular glycolipids of unknown structure and function, composed of neuraminic acid, sphingosine, fatty acids, hexoses and a hexosamine ${ }^{1-4}$. Structural evidence has now been obtained by acid hydrolytic cleavage of a highly purified preparation of brain ganglioside. A glucocerebroside has been isolated and the structure of the repeating unit formulated.

A stepwise procedure has been developed by which small fragments are successively cleaved from the water-soluble macromolecule, and separated quantitatively and gently from the balance of the molecule by exhaustive dialysis through 'Cellophane'. Both the dialysable and non.dialysable hydrolytic products are analysed at each step in terms of dry weight, titratable acidity, nitrogen, amino-nitrogen, neuraminic acid, hexosamine, hexose, and reducing sugar, partitioned by paper chromatographic and ionexchange procedures, and the subfractions further hydrolysed and analysed. Earlier studies $^{2,3}$ have demonstrated the hexoses to be exclusively glucose and galactose, and the hexosamine to be galactosamine.

In the present work, bovine brain ganglioside was prepared $d^{2,3}$ as an ash-free fraction (I) homogeneous by electrophoretic and ultracentrifuge studies (minimal molecular weight 250,000 ), completely watersoluble, free of phosphatides (P, 0.07 per cent) and of dialysable contaminants. (I) contains nitrogen 2.9 per cent, hexose $24 \cdot 0$ per cent (expressed as galactose) and galactosamine $10 \cdot 0$ per cent.

A 2 per cent aqueous solution of (I) is autohydrolysed at $100^{\circ} \mathrm{C}$. for a critical time interval of 